\title{
PEMODELAN REGRESI PROSES GAUSSIAN MENGGUNAKAN FUNGSI PERAGAM EKSPONENSIAL KUADRAT
}

\author{
Moch. Abdul Mukid ${ }^{1}$ \\ ${ }^{1}$ Staf Pengajar Program Studi Statistika FMIPA UNDIP
}

\begin{abstract}
Gaussian Process is a collection of random variables where any finite subset of that has a joint multivariate Gaussian distribution. A Gaussian Process is fully specified by its mean and its covariance function. One of the popular covariance functions is squared exponential that has two hyperparameters. In this paper Gaussian Process is used to made a prediction of the number of clothes produced by PT. APAC INTI CORPORA based on the number of attending employes, the number of overtime employes, the number of brokendown machines and used materials.
\end{abstract}

Keywords: Gaussian Process, Covariace Functions, Squared Exponential

\section{Pendahuluan}

Regresi proses Gaussian pertama kali diusulkan oleh O'Hagan (1978) sebagai sebuah alternatif pendekatan untuk model jaringan syaraf tiruan. Neal (1995) berargumen bahwa tidak ada alasan untuk percaya bahwa dalam permasalahan yang riil, model-model jaringan syaraf tiruan hanya memuat "sedikit" unit-unit tersembunyi. Ia telah menunjukkan bahwa dengan menggunakan unit-unit tersembunyi yang jumlahnya banyak akan menghasilkan prediksi-prediksi yang lebih baik. Ia juga menunjukkan bahwa pada modelmodel jaringan syaraf tiruan, bobot dari unit-unit tersembunyi yang jumlahnya banyak tersebut dalam kerangka Bayesian akan konvergen ke suatu prior proses Gaussian. Proses Gaussian adalah sebaran atas fungsi dimana nilai tengah dan ragam (peragam) nya adalah suatu fungsi tertentu.

Regresi proses Gaussian dapat dijelaskan dari sudut pandang regresi nonparametrik Bayesian, yaitu dengan menempatkan secara langsung sebaran prior Gaussian bagi fungsifungsi regresi $f(\mathbf{x})^{[9]}$. Beberapa peneliti telah menggunakan pendekatan regresi proses Gaussian untuk mengembangkan model dari kasus-kasus yang dihadapinya.Williams dan Rassmusen (2006) menggunakan regresi proses Gaussian untuk mendapatkan model gerak lengan robot dan Chen et al. (2007) menggunakan regresi proses Gaussian untuk mengembangkan model kalibrasi pada data-data spektroskopi.

Penelitian ini bertujuan untuk mengkaji dan menerapkan regresi proses Gaussian pada pemodelan prediksi jumlah produksi kain di PT. APAC INTI CORPORA berdasarkan peubah-paubah jumlah karyawan yang hadir, jumlah karyawan yang lembur, jumlah bahan baku yang digunakan dan jumlah mesin yang rusak.

\section{Tinjauan Pustaka}

\subsection{Regresi Proses Gaussian}

Proses stokastik adalah suatu kumpulan dari peubah-peubah acak $\left\{Y_{\mathbf{x}} \mid \mathbf{x} \in X\right\}$ yang diindekskan dengan sebuah himpunan $X$ yang beranggotakan $d$ peubah. Proses-proses stokastik ditentukan oleh pemberian sebaran peluang bersama untuk setiap himpunan bagian manapun dari $Y_{\mathbf{x}_{1}}, \ldots, Y_{\mathbf{x}_{\mathbf{k}}}$ dengan sebuah cara yang konsisten. Proses Gaussian adalah suatu proses stokastik dimana himpunan berhingga manapun dari himpunan peubah 
acak $Y$ mempunyai sebaran bersama Gaussian ganda ${ }^{[9]}$. Sebuah proses Gaussian ditentukan oleh fungsi rataan $\mu(\mathbf{x})=E\left[Y_{\mathbf{x}}\right]$ dan fungsi peragam $k\left(\mathbf{x}_{i}, \mathbf{x}_{j}\right)=E\left[\left(Y_{\mathbf{x}_{i}}-\mu\left(\mathbf{x}_{i}\right)\right)\left(Y_{\mathbf{x}_{j}}-\mu\left(\mathbf{x}_{j}\right)\right)\right]$.

Regresi proses Gaussian dapat diturunkan dari sudut pandang regresi nonparametric Bayesian yaitu dengan menempatkan secara langsung sebaran prior Gaussian bagi fungsi-fungsi regresi $f(\mathbf{x})^{[9]}$. Misal untuk setiap output $y_{i}$ bergantung pada input $\mathbf{x}_{\mathbf{i}}$ dibawah sebuah fungsi $f_{i}$ sebagai berikut:

$$
y_{i}=f\left(\mathbf{x}_{i}\right)+\varepsilon_{i}
$$

dengan $\varepsilon_{i}$ adalah peubah acak galat yang secara bebas dan identik menyebar Gaussian dengan rataan nol dan ragam $\sigma^{2}$, sedangkan $\mathbf{x}_{i}$ adalah vektor input ke-i dengan $i=1, \ldots \ldots$, n. Apabila fungsi-fungsi $f$ dikumpulkan dalam sebuah vektor $\mathbf{f}=\left[f_{1}, \cdots, f_{n}\right]^{T}$ maka menurut Proses Gaussian untuk metode regresi , sebaran prior atas vektor $\mathbf{f}$ adalah Gaussian ganda dengan vektor rataan $\mathbf{0}$ dan matrik peragam $\mathbf{K}$, yaitu

$$
\mathbf{f} \mid \mathbf{X}, \boldsymbol{\theta} \sim N(\mathbf{0}, \mathbf{K})
$$

dengan $\mathbf{K}$ adalah matrik n x n yang bergantung pada $\mathbf{X}$ dan $\boldsymbol{\theta}$ sedangkan $\boldsymbol{\theta}$ adalah vektor parameter dari fungsi peragam. Setiap elemen ke (i,j) dari matrik $\mathbf{K}$ adalah $k\left(\mathbf{x}_{i} \mathbf{x}_{j}\right)$ dengan $k(. .$.$) adalah sebuah fungsi yang definit non negatif yang memuat parameter \boldsymbol{\theta}$. Selanjutnya $k(.,$.$) disebut sebagai fungsi peragam.$

Persamaan (1) dapat dinyatakan dalam bentuk persamaan vektor, yaitu

$$
\mathbf{y}=\mathbf{f}+\boldsymbol{\varepsilon}
$$

dengan $\mathbf{y}$ adalah vektor amatan dari respon, $\mathbf{f}$ adalah vektor dari fungsi-fungsi regresi dan $\varepsilon$ adalah vektor galat.

Sebagai implikasi langsung atas penetapan sebaran prior Gaussian ganda bagi vektor $\mathbf{f}$ dan asumsi bahwa vektor galat $\boldsymbol{\varepsilon}$ menyebar Gaussian dengan nilai tengah $\mathbf{0}$ maka sebaran bagi vektor amatan $\mathbf{y}$ adalah Gaussian ganda dengan nilai tengah $\mathbf{0}$ dan matrik ragam peragam $\mathbf{K}+\sigma^{2} \mathbf{I}$. Tidak setiap vektor amatan $\mathbf{y}$ selalu memiliki nilai tengah $\mathbf{0}$ sehingga untuk memenuhinya, setiap amatan dari $y_{\mathrm{i}}$ akan dikurangi dengan nilai rata-rata dari keseluruhan amatan.

\subsection{Fungsi Peragam Eksponensial Kuadrat}

Fungsi peragam adalah sebuah fungsi dari input-input model yang menghasilkan sebuah nilai peragam bagi output-output yang bersesuaian ${ }^{[6]}$. Satu-satunya syarat bagi sebuah fungsi peragam adalah mampu membangkitkan sebuah matrik ragam peragam yang definit non negatif untuk sembarang himpunan titik-titik input.

Salah satu jenis fungsi peragam yang sering digunakan dalam pemodelan dengan menggunakan regresi proses Gaussian adalah fungsi peragam eksponesial kuadrat. Formula matematik dari fungsi peragam eksponesial kuadrat dengan sebuah peubah bebas adalah

$$
k\left(x_{i}, x_{j}\right)=\sigma_{f}^{2} \exp \left[\frac{-\left(x_{i}-x_{j}\right)^{\pi}}{2 l^{\mathrm{N}}}\right]
$$

dengan $x_{i}, x_{j}$ masing-masing adalah input ke-i dan ke-j yang bersesuaian dengan peubah bebas $x . \sigma_{f}^{2}$ adalah ragam signal yang menunjukkan nilai peragam dari dua buah output jika input-inputnya sangat berdekatan $\left(x_{i} \approx x_{j}\right)$. Tampak bahwa jika posisi $x_{i}$ sangat jauh dari $x_{j}$ maka nilai $k\left(x_{i}, x_{j}\right) \approx 0$. Dengan kata lain kedua titik input tersebut tidak dapat 
saling "melihat" antara satu dengan lainnya. Hal ini berarti bahwa pada saat interpolasi terhadap nilai-nilai baru $x$, jarak observasi akan menyebabkan efek yang dapat diabaikan. Seberapa besar efek dari pemisahan ini bergantung pada panjang dari parameter $l$.

Jika input terdiri atas $p$ peubah bebas maka formula matematik dari fungsi peragam eksponensial kuadrat adalah

$$
k\left(\mathbf{x}_{i j}, \mathbf{x}_{j}\right)=\sigma_{f}^{2} \exp \left[\sum_{m=1}^{p} \frac{-\left(\mathbf{x}_{m i}-\mathbf{x}_{m i j}\right)^{2}}{21_{m}^{2}}\right]
$$

Jika nilai $l_{m}$ dianggap sama untuk setiap $m=1,2, \ldots, \mathrm{p}$ maka fungsi peragam tersebut dinamakam Eksponensial Kuadrat Isotropic (EK-Iso), namun jika nilai-nilainya dianggap berbeda fungsi peragam tersebut dinamakan Eksponensial Kuadrat Automatic Relevance Determinant (EK-ARD). Nilai parameter $l_{m}$ menunjukkan tingkat "penting" dari peubah bebas yang bersesuaian. Makin kecil nilai $l_{m}$ menunjukkan makin penting peubah bebas tersebut bagi proses prediksi, sebaliknya makin besar nilai $l_{m}$ menunjukkan makin tidak penting peubah bebas tersebut. Untuk selanjutnya parameter-parameter $\sigma_{f}^{2}$ dan $l_{m}$ disebut dengan hyperparameter. Istilah ini digunakan semata-semata untuk menunjukkan bahwa parameter-paraneter tersebut bukan merupakan parameter dari sebuah model.

\subsection{Pendugaan Hiperparameter Fungsi Peragam}

Terdapat beberapa metode yang dapat digunakan untuk menduga nilai-nilai hiperparameter. Williams (2002) menyatakan bahwa untuk menduga nilai $\boldsymbol{\theta}$ dapat digunakan metode kemungkinan marginal maksimum ( Maximum Marginal Likelihood), metode aposterior maksimum, dan metode simulasi hybrid Monte Carlo. Metode lain yang bisa digunakan adalah metode Cross Validation dan Generalized Cross Validation ${ }^{[9]}$.

Pada tulisan ini, pendugaan nilai hiperparameter menggunakan metode kemungkinan marginal maksimum. Fungsi kemungkinan marginal diperoleh dengan mengintegralkan fungsi kemungkinan yang telah dikalikan dengan sebaran prior bagi $\mathbf{f}$, yaitu:

$$
p(\mathbf{y} \mid \mathbf{X}, \boldsymbol{\theta})=\int p(\mathbf{y} \mid \mathbf{f}, \mathbf{X}, \boldsymbol{\theta}) p(\mathbf{f} \mid \mathbf{X}, \boldsymbol{\theta}) d \mathbf{f}
$$

Dibawah kerangka kerja Proses Gaussian, sebaran prior bagi $\mathbf{f} \mid \mathbf{X}, \boldsymbol{\theta}$ adalah Gaussian ganda, yaitu $\mathbf{f} \mid \mathbf{X}, \boldsymbol{\theta} \sim N(\mathbf{0}, \mathbf{K})$ yaitu:

$$
p(\mathbf{f} \mid \mathbf{X}, \boldsymbol{\theta})=\frac{1}{(2 \pi)^{n / 2}|\mathbf{K}|^{1 / 2}} e^{-\frac{1}{2} \mathbf{f}^{T} \mathbf{K}^{-1} \mathbf{f}}
$$

atau

$$
\log p(\mathbf{f} \mid \mathbf{X}, \boldsymbol{\theta})=-\frac{1}{2} \mathbf{f}^{T} \mathbf{K}^{-1} \mathbf{f}-\frac{1}{2} \log |\mathbf{K}|-\frac{n}{2} \log 2 \pi
$$

Peubah acak $\mathbf{y} \mid \mathbf{f}, \mathbf{X}, \boldsymbol{\theta}$ dan $\mathbf{f} \mid \mathbf{X}, \boldsymbol{\theta}$ masing-masing menyebar Gaussian Ganda sehingga peubah acak $\mathbf{y} \mid \mathbf{X}, \boldsymbol{\theta}$ menyebar Gaussian ganda juga ${ }^{[8]}$, sehingga fungsi kemungkinan marginalnya adalah ${ }^{[6]}$

$$
\log p(\mathbf{y} \mid \mathbf{X}, \boldsymbol{\theta})=-\frac{1}{2} \mathbf{y}^{T}\left(\mathbf{K}+\sigma^{2} \mathbf{I}\right)^{-1} \mathbf{y}-\frac{1}{2} \log \left|\mathbf{K}+\sigma^{2} \mathbf{I}\right|-\frac{n}{2} \log 2 \pi
$$

Penduga bagi hiperparameter fungsi peragam tidak dapat diperoleh secara langsung melalui statistik penduganya, oleh karena itu untuk menemukan nilai dugaannya dilakukan secara numerik. Salah satu metode yang dapat digunakan adalah metode Conjugate Gradient ${ }^{[2]}$. Metode Conjugate gradient adalah sebuah algoritma yang dirancang untuk menemukan nilai minimum lokal terdekat dari fungsi banyak peubah 
dengan syarat gradien dari fungsi tersebut dapat dihitung. Usaha untuk memaksimumkan fungsi kemungkinan marginal ekuivalen dengan meminimumkan fungsi kemungkinan marginal negatif.

\subsection{Prediksi Dalam Regresi Proses Gaussian}

Misal diberikan beberapa amatan dan sebuah fungsi peragam. Selanjutnya akan ditentukan nilai prediksinya dengan menggunakan model proses Gaussian. Untuk melakukan hal itu, jika $\mathbf{x}^{*}$ sebuah titik uji dan $f^{*}$ adalah fungsi yang bersesuaian dengan $\mathbf{x}^{*}$, maka dibawah kerangka kerja Proses Gaussian, sebaran bersama dari $\mathbf{f}$ dan $f^{*}$ adalah Gaussian Ganda dengan rataan nol, yaitu:

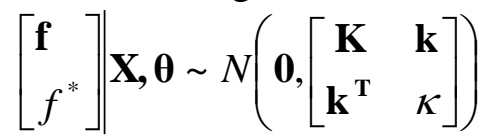

dengan $\mathbf{k}=\left[k\left(\mathbf{x}^{*}, \mathbf{x}_{1}\right), \ldots, k\left(\mathbf{x}^{*}, \mathbf{x}_{n}\right)^{T}\right.$ adalah vektor $\mathrm{n} \mathbf{x} 1$ yang dibentuk dari peragam antara $\mathbf{x}^{*}$ dan input-input model. Sedangkan $\kappa=k\left(\mathbf{x}^{*}, \mathbf{x}^{*}\right)$ adalah sebuah skalar. Apabila peubah galat mengikuti sebaran seperti pada persamaan (1) maka sebaran bersama dari nilai teramati $\mathbf{y}$ dan $y^{*}$ adalah

$$
\left[\begin{array}{l}
\mathbf{y} \\
y^{*}
\end{array}\right] \mid \mathbf{X}, \boldsymbol{\theta} \sim N\left(\mathbf{0},\left[\begin{array}{cc}
\mathbf{K}+\sigma^{2} \boldsymbol{I} & \mathbf{k} \\
\mathbf{k}^{\mathbf{T}} & \kappa+\sigma^{2}
\end{array}\right]\right)
$$

Sehingga sebaran marginal dari $y^{*}$ adalah Gaussian juga, yaitu :

$$
y^{*} \mid \mathbf{y}, \mathbf{X}, \boldsymbol{\theta} \sim N\left(m\left(\mathbf{x}^{*}\right), v\left(\mathbf{x}^{*}\right)\right)
$$

dengan rataan dan ragamnya adalah

$$
\begin{aligned}
& m\left(\mathbf{x}^{*}\right)=\mathbf{k}^{\mathbf{T}}\left(\mathbf{K}+\sigma^{2} \mathbf{I}\right)^{-1} \mathbf{y} \\
& v\left(\mathbf{x}^{*}\right)=\kappa+\sigma^{2}-\mathbf{k}^{\mathbf{T}}\left(\mathbf{K}+\sigma^{2} \mathbf{I}\right)^{-1} \mathbf{k}
\end{aligned}
$$

Nilai dugaan bagi $y^{*}$ adalah $m\left(\mathbf{x}^{*}\right)$ dan ragam bagi dugaan $y^{*}$ adalah $v\left(\mathbf{x}^{*}\right)$. Secara umum untuk $m$ buah titik uji $\mathbf{X}^{*}=\left[\mathbf{x}_{1}^{*}, \ldots, \mathbf{x}_{m}^{*}\right]$ maka sebaran $\mathbf{y}^{*}$ adalah Gaussian Ganda dengan parameter-parameter,

$$
\begin{aligned}
& m\left(\mathbf{X}^{*}\right)=\mathbf{K}^{* \mathbf{T}}\left(\mathbf{K}+\sigma^{2} \mathbf{I}\right)^{-1} \mathbf{y} \\
& v\left(\mathbf{X}^{*}\right)=\mathbf{K}^{* *}+\sigma^{2} \mathbf{I}-\mathbf{K}^{* \mathbf{T}}\left(\mathbf{K}+\sigma^{2} \mathbf{I}\right)^{-1} \mathbf{K}
\end{aligned}
$$

dengan $\mathbf{K}^{*}$ adalah matrik $n \times m$ dari peragam antara input-input training dan titik-titik uji.

Matrik $\mathbf{K}^{* *}$ dengan ukuran $\mathrm{m} x \mathrm{~m}$ tersusun dari peragam antara titik-titik uji.

Kinerja dari model regresi proses Gaussian dalam melakukan prediksi diukur berdasarkan nilai RMSE (Root Mean Square Error) yang diperoleh. Makin kecil nilai RMSE maka makin baik pula kinerja dari model tersebut.

\section{Bahan Dan Metode}

\subsection{Sumber Data}

Data yang digunakan dalam penelitian ini adalah data sekunder yang berasal dari Production Performance Plan yang dimiliki oleh PT. APAC INTI CORPORA. Peubahpeubah yang diamati adalah jumlah produksi kain yang diukur dalam satuan meter, jumlah karyawan yang hadir yang diukur dalam satuan orang, jumlah karyawan yang lembur yang diukur dalam satuan orang, jumlah bahan baku yang digunakan yang dukur dalam satuan bal, dan jumlah mesin yang rusak yang diukur dalam satuan buah. Pengukuran terhadap 
peubah-peubah tersebut dilakukan dari tanggal 12 Agustus sampai dengan 5 September 2007.

\subsection{Metode Analisis}

Langkah-langkah dalam pemodelan regresi proses Gaussian secara garis besar adalah sebagai berikut:

a. Menguji sebaran Gaussian bagi peubah tak bebas (jumlah kain yang diproduksi)

b. Menetapkan jenis fungsi peragam yang akan digunakan

c. Memprediksi respon dengan formûtila $\mathbf{k}^{\mathbf{T}}\left(\mathbf{K}+\sigma^{2} \mathbf{I}\right)^{-1} \mathbf{y}$

d. Menguji sebaran Gaussian bagi residual

e. Menghitung nilai RMSE

\section{Hasil Dan Pembahasan}

Beberapa asumsi pada pemodelan dengan menggunakan proses Gaussian adalah bahwa peubah tak bebasnya (jumlah produksi kain) dan residual mengikuti sebaran Gaussian (normal). Berdasarkan Gambar 1, dengan menggunakan uji KolmogorovSmirnov pada taraf nyata $5 \%$, dapat disimpulkan bahwa jumlah produksi kain di PT. APAC INTI CORPORA WEAVING III TOYODA Bawen menyebar normal dengan rata-rata 63081 bal dan simpangan baku 3826 bal. Nilai p-value yang diperoleh pada pengujian sebaran ini lebih besar dari 0,150.

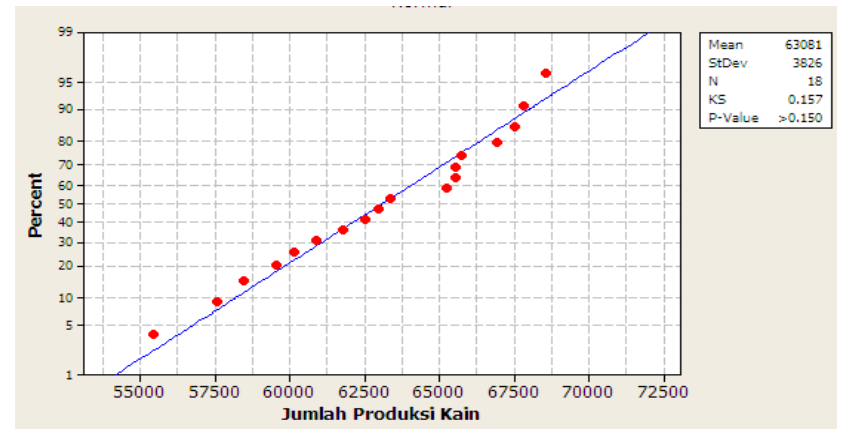

Gambar 1. Plot Peluang Normal Peubah Acak Jumlah Produksi Kain

Berdasarkan Gambar 2, dengan menggunakan uji Kolmogorov-Smirnov pada taraf nyata 5\%, dapat disimpulkan bahwa peubah acak residual menyebar normal dengan nilai tengah yang mendekati nol dan simpangan baku sebesar 0,00008. Nilai p-value yang diperoleh pada pengujian sebaran ini lebih besar dari 0,150 .

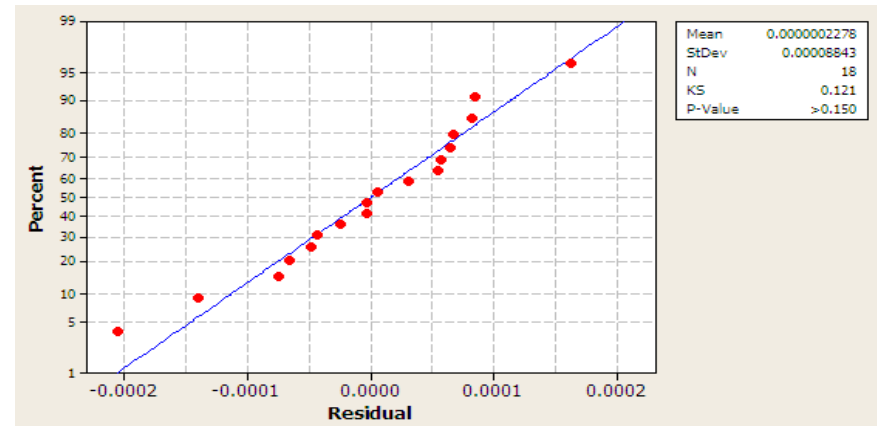

Gambar 2. Plot Peluang Normal Peubah Acak Galat 
Asumsi-asumsi yang dibutuhkan pada pemodelan dengan pendekatan regresi proses gaussian telah terpenuhi, oleh karena itu proses prediksi terhadap output berdasarkan nilainilai inputnya dapat dilakukan. Aspek penting dalam pemodelan regresi proses gaussian adalah pemilihan fungsi peragam. Dalam penelitian ini digunakan fungsi peragam Eksponensial Kuadrat Automatic Relevance Determinant (EK-ARD). Apabila pemodelan tehadap fungsi peragamnya mengandung galat maka formula bagi fungsi peragam EK-ARD menjadi

$$
k\left(\mathbf{x}_{i j}, \mathbf{x}_{j}\right)=\sigma_{f}^{2} \exp \left[\sum_{m=1}^{p} \frac{-\left(\mathbf{x}_{m i}-\mathbf{x}_{m j}\right)^{2}}{2 l_{m}^{2}}\right]+\sigma_{m}^{2} \delta_{i j}
$$

dengan $\delta_{i j}=1$ untuk $i=j$ dan $\delta_{i j}=0$ untuk $i \neq j$. Tampak bahwa vektor hiperparameter bagi fungsi peragam EK-ARD adalah $\left(l_{1}, l_{2}, l_{3}, l_{4}, \sigma_{f}^{2}, \sigma_{n}^{2}\right)$. Nilai-nilai hiperparameter tersebut diduga dengan menggunakan metode kemungkinan marginal maksimum, seperti terlihat pada Tabel 1 yang berisi nilai dugaan terhadap hiperparameter-hiperparameter dari fungsi peragam EK-ARD.

Berdasarkan nilai dugaan terhadap hiperparameternya, "tingkat penting" dari peubah-peubah bebas dapat diketahui. Dari Tabel 1, tampak bahwa peubah bebas jumlah bahan baku relatif menempati posisi paling penting dibanding dengan peubah-peubah bebas lainnya yang digunakan dalam pembentukan model prediksi bagi jumlah produksi kain. Hal ini karena nilai dugaan bagi parameter $l$ (skala panjang) yang bersesuaian dengan peubah bebas jumlah bahan baku adalah yang terkecil nilainya, yaitu sebesar 3,3. Secara keseluruhan peubah bebas jumlah karyawan yang lembur menempati urutan penting kedua, jumlah mesin yang rusak menempati urutan penting ketiga dan urutan penting yang keempat adalah jumlah karyawan yang hadir.

Tabel 1. Nilai Dugaan Hiperparameter

\begin{tabular}{|c|c|}
\hline Hyperparameter & $\begin{array}{c}\text { Nilai } \\
\text { Dugaan }\end{array}$ \\
\hline$l_{1}$ & 17.9 \\
\hline$l_{2}$ & 8.2 \\
\hline$l_{3}$ & 12.1 \\
\hline$l_{4}$ & 3.3 \\
\hline$\sigma_{f}^{2}$ & 3716.9 \\
\hline$\sigma_{n}^{2}$ & 0.5 \\
\hline
\end{tabular}

Tabel 2. Urutan Tingkat Penting dari Peubah Bebas Berdasarkan Nilai Dugaan Hiperparameter

\begin{tabular}{|l|c|c|}
\hline \multicolumn{1}{|c|}{ Peubah } & $\begin{array}{c}\text { Rangking } \\
\text { (Tingkat Penting) }\end{array}$ & $\begin{array}{c}\text { Nilai Dugaan } \\
\text { Hyperparameter }\end{array}$ \\
\hline Jumlah bahan baku & 1 & 3.3 \\
\hline Jumlah karyawan lembur & 2 & 8.2 \\
\hline Jumlah mesin rusak & 3 & 12.1 \\
\hline Jumlah karyawan yang hadir & 4 & 17.9 \\
\hline
\end{tabular}


Implementasi regresi proses Gaussian dengan menggunakan fungsi peragam KEARD untuk model prediksi jumlah produksi kain di PT. APAC INTI CORPORA WEAVING III TOYODA Bawen menghasilkan nilai RMSE sebesar 0,000086. Ini adalah sebuah nilai yang sangat kecil.

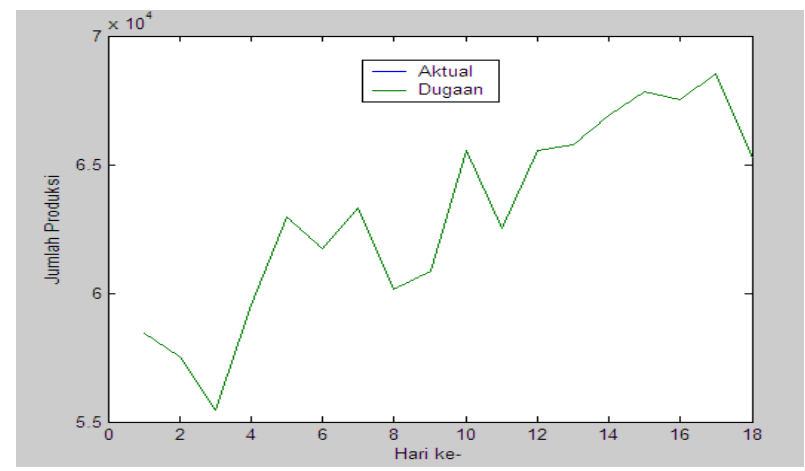

Gambar 3. Plot antara Nilai Aktual dan Nilai Dugaan Jumlah Produksi Kain

Gambar 3 adalah Plot antara nilai aktual dan nilai dugaan jumlah produksi kain. Tampak bahwa posisi nilai aktual dan dugaannya hampir berimpit. Hal ini menunjukkan bahwa pengembangan model prediksi bagi jumlah produksi kain di PT. APAC INTI CORPORA dengan pendekatan regresi proses Gaussian relative baik untuk digunakan.

\section{Kesimpulan}

Melakukan prediksi terhadap nilai dari sebuah peubah acak berdasarkan pada peubah-peubah penjelas yang telah diidentifikasi sebelumnya adalah sebuah aktifitas yang sering dilakukan, khususnya bagi para manajer, supervisor produksi dan para pengguna statistik pada umumnya. Usaha ini dilakukan untuk meminimalkan ketidakpastian di titiktitik waktu yang akan datang. Regresi proses Gaussian adalah salah satu metode yang dapat digunakan untuk melakukan hal itu. Metode ini termasuk dalam kategori regresi non parametrik dimana spesifikasi model yang menghubungkan antara peubah tak bebas dengan peubah-peubah bebas tidak perlu ditetapkan terlebih dahulu. Data dibiarkan "berbicara sendiri" untuk membentuk struktur model yang relevan. Ketika metode ini diterapkan untuk memprediksi jumlah produksi kain di PT. APAC INTI CORPORA, nilai RMSE yang dihasilkan relative kecil, yaitu 0,000086. Hal ini menunjukkan bahwa pengembangan model prediksi bagi jumlah produksi kain di PT. APAC INTI CORPORA WEAVING III TOYODA Bawen dengan pendekatan regresi proses Gaussian relative baik untuk digunakan.

\section{DAFTAR PUSTAKA}

1. Chen, T, Morris, J, and Martin, E., Gaussian Process Regression for Multivariate Spectroscopic Callibration, Chemometrics and Intelligent Laboratory Systems, 2007, 87: 85-97.

2. Fletcher, R, and Reeves, C.M., Function Minimization by Conjugate Gradients, Computer Journal, 1964, 7:148-154.

3. MacKay, D.J.C., Introduction to Gaussian Processes, di dalam: Bishop, C.M., Neural Networks and Machine Learning, Springer-Verlag, New York, 1998.

4. Neal, R.M., Bayesian Learning for Neural Network, Springer-Verlag, New York, 1995. 
Media Statistika, Vol. 3, No. 1, Juni 2010: 1-8

5. O'Hagan, Curve Fitting and Optimal Design for Prediction (with discussion), Journal of the Royal Statistical Society, 1978, 40: 1-40.

6. Rasmussen, C.E., Evaluation of Gaussian Processes and Other Methods for Non Linear Regression, Disertasion, Department of Computer Science, University of Toronto, 1996.

7. Rasmussen, C.E., and Williams, C.K.I., Gaussian Process for Machine Learning, MIT Press, Massachusetts, 2006.

8. Timm, N.H., Applied Multivariate Analysis, Springer-Verlag, New York, 2002.

9. Williams, C.K.I., Rasmussen, C.E., Schwaighofer, A., and Tresp, V., Observations on the Nystrom Method for Gaussian Process Prediction, Technical Report, University of Edinburgh, 2002. 